\title{
Breast Tuberculosis after Chest Trauma - a Case Report and Review of the Literature
}

\author{
Claudio Perrone $^{a} \quad$ Alfonso M. Altieri ${ }^{a}$ Salvatore D'Antonio ${ }^{a}$ Clara Leonetti ${ }^{b}$ Mario G. Alma ${ }^{a}$ \\ a Unit of Pneumology and Phthisiology 'San Camillo-Forlanini' Hospital, Rome, Italy; \\ bUnit of Radiology, 'San Camillo-Forlanini' Hospital, Rome, Italy
}

\section{Established Facts}

- Tuberculosis can involve the breast and may mimic breast cancer.

- An accurate microbiologic analysis should be performed in every breast lesion of unknown origin.

\section{Novel Insights}

- Nuclear magnetic resonance imaging can provide valuable information on the nature of the breast lesions.

- Breast tuberculosis just after chest trauma, which has not been reported previously, could disclose new pathogenetic mechanisms of mycobacterium tuberculosis complex diffusion.

\section{Keywords}

Breast · Tuberculosis · Trauma

\section{Summary}

Background: Breast involvement of tuberculosis (TB) is well known but uncommon. It can resemble other diseases, including breast cancer, and diagnosis is quite difficult. So, when facing a breast lesion, a possible tubercular etiology should always be born in mind, relying on qualified laboratories to confirm the diagnosis. Case Report: We describe a 42-year-old woman with a mammary fistula complicating a post-traumatic lump. A critical analysis of the diagnostic process was performed together with a review of the literature, also considering the potential role of trauma in inducing such a rare complication.

\section{Introduction}

Although tuberculosis (TB) is today a worldwide public health concern, breast involvement is uncommon [1-3]. It occurs more often during the reproductive age, in multiparous, lactating women, and in endemic areas; nevertheless, in Europe, major attention to breast involvement is advocated [4-6]. Its clinical presentation can resemble pyogenic abscesses and breast cancer; its diagnosis is often inaccurate or delayed.

We report a patient with a previous chest trauma followed by a left breast lump and fistulization. An analysis of the laborious diagnostic process follows, with some considerations concerning the pathogenesis.

\section{Case Report}

A 42 -year-old Ukrainian woman suffered a blunt trauma at the chest, by falling off a ladder. She had a 17-year-old son and a 5-year-old daughter. She never smoked. She complained about pain and a progressive swelling of the left breast, where a large hematoma had become evident. After a few days, fever

\section{KARGER



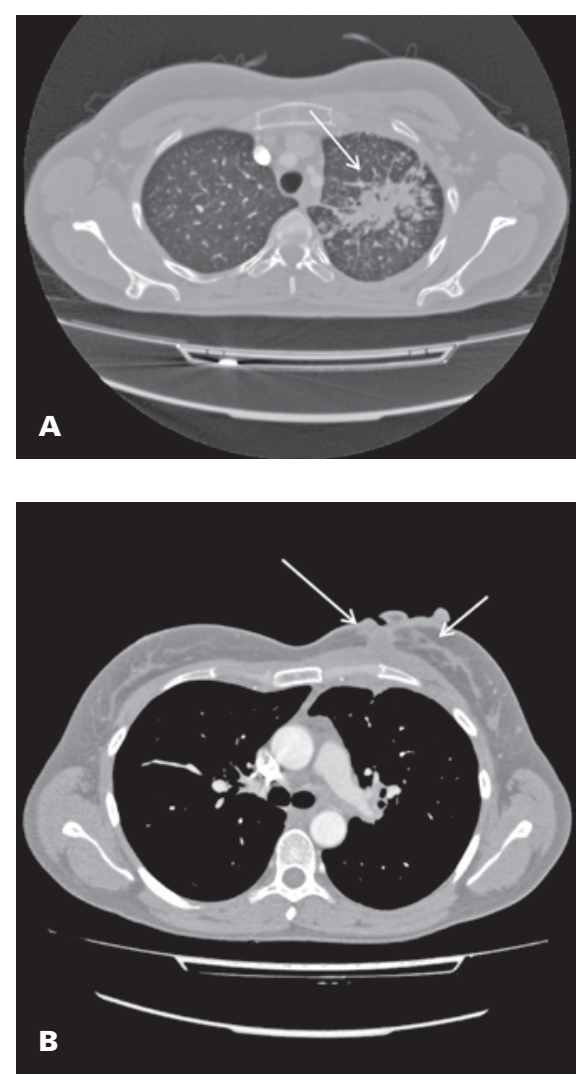

Fig. 1. A The $C T$ shows opacities in the left superior lobe (arrow). B Involvement of subcutaneous tissue was also detectable, with a fistula opening in the upper internal quadrant of the left breast.

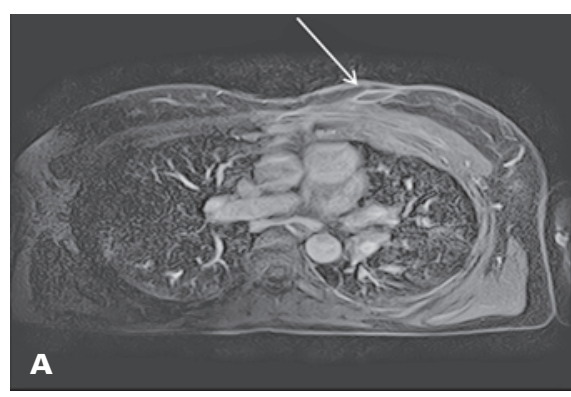

Fig. 2. A NMR better shows the profile of the fistula in the mammarian tissue, defining its existence. B Arrows indicate 2 different major fistula ducts through the glandular tissue and the muscular chest wall.

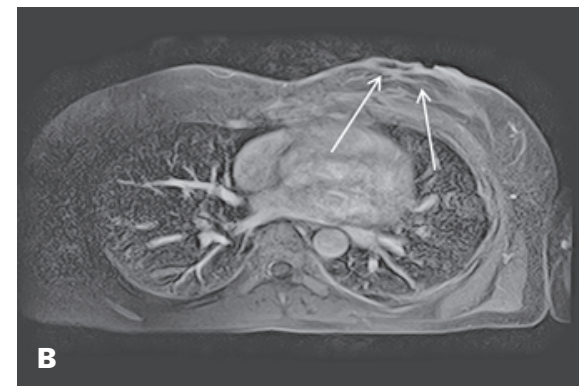

\section{Discussion}

TB should always be considered in the first evaluation of a breast lesion, also in Western countries. Furthermore, considering risk factors, our patient was rather far advanced through the years of her reproductive age and was, of course, not lactating, but she comes from a high-TB burden country such as the Ukraine. It is then mandatory to perform an accurate clinical and radiological examination of the chest, even in the absence of pulmonary symptoms.

Mammary TB was described in 1829 [7]: A primary involvement occasionally exists $[8,9]$, whereas secondary forms are less uncommon [10]. Considering lung involvement, this patient constitutes a case of secondary breast TB. McKeown and Wilkinson [11] classified 5 different types of breast TB: (1) nodular tubercular mastitis, (2) disseminated or confluent tubercular mastitis, (3) sclerosing tubercular mastitis, (4) tuberculous mastitis obliterans, and (5) acute miliary tubercular mastitis. The pathways of MTC spreading to the breast are by hematogenic route, by lymphatic routes from the axillary, mediastinal, or cervical lymph nodes, or directly from underlying structures such as the ribs or pleura, or by the inoculation of infected sputum. Our patient presented a confluent tubercular mastitis; propagation through lymphatic structures is the most probable way of diffusion of MTC in this case.

The role of the chest trauma - coincidental or not - remains to be clarified. Since initial reports [12], trauma has been proposed as a possible risk factor for breast TB; damaged tissue may constitute an area of lessened resistfgance. Cases of extra-pulmonary TB were reported in sites of previous non-penetrating trauma [13]. For pathogenesis, other mechanisms have also been proposed, involving the transport of MTC by monocytes to sites of injury, opening new spaces for future research.

We want to stress the link, at least a temporal one, between surgical maneuvers and the diagnosis of pulmonary TB. There was no 
$\mathrm{X}$-ray of the chest that could have resulted in a breast abscess, nor were there clinical symptoms or signs to determine the exact period of the insurgence of lung involvement, and the hypothesis of a primary breast TB cannot be sustained with absolute certainty. In the past, a correlation has been reported between the reactivation of pulmonary $\mathrm{TB}$ and gastrectomy $[14,15]$; the pathogenesis remained speculative. Cases of extra-pulmonary TB reactivation after surgery of the hip have been reported $[16,17]$. To our knowledge, no cases have been described of pulmonary TB reactivation just after surgery and/or invasive procedures on the chest; it is, however, plausible that repeated minor and major surgical procedures, with the reactivation of a latent infection, may have facilitated local MTC diffusion.

Other infective agents, e.g. non-tubercular mycobacteria, could induce mammary lesions, sometimes just after a trauma $[18,19]$. An idiopathic granulomatous mastitis has been described as a rare benign inflammatory breast disease that is frequently mistaken for breast carcinoma [20]; its etiology is unknown, but some cases have been associated with previous breast trauma [21].

Of course, in the face of breast lesions involving the chest wall, it is mandatory to rule out cancer. Moreover, TB and cancer may coexist [22].

In fact, some data (absence of response to antibiotics, HRCT evidence of solid lesions in the left lung without significant infectious symptoms, appearance of orange peel-like skin followed by fistulization) could hint at a potential cancer. Notably, neither mammography nor fine-needle ago-biopsy (FNAB) was performed. In turn, an FNAB should always be performed when suspecting breast cancer [23]. Furthermore, the great potential of MRI scans in defining breast lesions has to be stressed [24]. By MRI, we obtained a better definition of the extension of the abscesses and fistulae through the tissue, which CT did not show as well. MRI can be a good tool in every case of a doubtful breast lesion, as it is a non-invasive tool and - especially in young women - it is free from collateral effects due to radiation.
However, breast tissue remains usually resistant to MTC: By 1982 , only 500 cases were collected by examining the entire world literature [25], and till 1987, less than 100 cases were reported from India [26]. Most of the cases described until today have occurred in India, with a global incidence of less of $4.5 \%$ of the totality of the mammary pathologies [27]. The best way to make a diagnosis remains by considering the following: difficulties encountered in excluding pyogenic abscesses or neoplasms. To our knowledge, this is the first case of pulmonary TB with breast involvement reported after a trauma. We can refer our samples to highly qualified histologic and microbiologic laboratories, which immediately perform GeneXpert analyses on positive samples to identify MTC and resistance to rifampicin, and then make an antibiogram to test resistances to major anti-mycobacterial drugs, such as isoniazid in this case. This approach is critical for our diagnostic and therapeutic successes.

\section{Conclusions}

Clinical awareness of TB is always necessary in evaluating breast lesions. Trauma could be a potential risk factor for the reactivation of a latent tubercular infection, and this link may disclose new mechanisms of MTC diffusion. Nuclear MRI is a non-invasive tool to obtain breast images with optimal definition; however, FNAB should be performed in every case of uncertain origin. Qualified microbiologic and histologic laboratories are essential for successful diagnostic and therapeutic processes.

\section{Disclosure Statement}

The authors declare no conflicts of interest.

\section{References}

1 Kalac N, Ozkan B, Bayiz H, Dursun AB, Demirag F: Breast tuberculosis. Breast 2002;11:346-349.

2 Tewari M, Shukla HS: Breast tuberculosis: diagnosis, clinical features, and management. Indian J Med Res 2005; 122:103-110.

3 Mehta G, Mittal A, Verma S: Breast tuberculosis - clinical spectrum and management. Indian J Surg 2010;72 (6) :433-447.

4 Jah A, Mulla R, Lawrence FD, Pittam M, Ravichandran D: Tuberculosis of the breast: experience of a UK breast clinic serving an ethnically diverse population. Ann R Surg Engl 2004;86:416-419.

5 Marinopoulos S, Lourantou D, Gatsionis T, Dimitrakakis C, Papaspyrou I, Antsaklis A: Breast tuberculosis: diagnosis, management and treatment. Int J Surg Case Rep 2012;3 (11) 548-550.

6 Meggiorini ML, Vitolo D, Russo A, Trinchieri V, De Felice C: Breast tuberculosis: rare but still present in Italy - a case of mycobacterium breast infection. Breast Dis 2011-2012;33 (4):177-182
7 Cooper A: Illustrations of the Diseases of the Breast, part I. London, Longman, Rees, Orme, Brown and Green, 1829, p 73.

8 Gupta R, Singal RP, Gupta A, Singal S, Shahi SR, Singal R: Primary tubercular abscess of the breast - an unusual entity. J Med Life 2012;5 (1):98-100.

9 Kachewar A, Sankaye S: Primary tubercular mastopathy. Australas Med J 2012;5 (8):436-439.

10 Wani A, Lone AM, Malik R, Wani KA, Wani RA, Hussain I, Thakur N, Snabel V: Secondary tuberculosis of breast: case report. ISRN Surg 2011;2011:529368.

11 McKeown KC, Wilkinson KW: Tuberculous disease of the breast. Br J Surg 1952;39:420.

12 Keeley JL: Tuberculosis of the breast. Ann Surg 1937; 105 (2) :169-176.

13 Barr DA, Whittington AM, White B, Patterson B, Davidson $\mathrm{RN}$ : Extra-pulmonary tuberculosis developing at sites of previous trauma. J Infect 2013;66 (4):313319.
14 Warthin TA: Reactivation of pulmonary tuberculosis in relation to subtotal gastrectomy for peptic ulcer. Trans Am Clin Climatol Assoc 1952;64:148-155.

15 Morandini GC, Rossi A: Gastro-duodenal ulcer, gastric resection and pulmonary tuberculosis. Clinico-statistical remarks on patients hospitalized in a TBC department, including those admitted within the last 20 years. G Ital Mal Torace 1967;21 (6):83-93.

16 Sennoune B, Koulali KI, Fnini S, Hachimi K, Ouarab M, Trafeh M: Tuberculous infection after dynamic-hip screw osteosynthesis: a case report. Rev Chir Orthop Reparatrice Appar Mot 2003;89 (3):257-260.

17 Walczak P, Rapala K, Nowak-Misiak M, Pykało R, Truszczynska A: Recurrence of tuberculosis after hip replacement 58 years after primary infection. Ortop Traumatol Rehabil 2012;14 (2):189-196.

18 Verfaillie G, Goossens A, Lamote J: Atypical mycobacterium breast infection. Breast J 2004;10:60. 
19 Yasar KK, Pehlivanoglu F, Sengoz G, Cabioglu N: Successfully treated Mycobacterium abscessus mastitis: rare cause of breast masses. Indian J Med Microbiol 2011;29 (4):425-427.

20 Hee RNS, Kuk YN, Hyun EY, Tae HK, Doo KK, Ki KO, Seok YK, Young-Sil A, Mison C, Woojae K RaeWP, Yong SJ, Ku SK: Differential diagnosis in idiopathic granulomatous mastitis and tuberculous mastitis. J Breast Cancer 2012;15 (1):111-118.

21 Patel RA, Strickland P, Sankara IR, Pinkston G, Many W, Rodriguez M: Idiopathic granulomatous mastitis: case reports and review of literature. J Gen Intern Med 2010;25 (3):270-273.
22 Tulasi NR, Raju PC, Damodaran V, Radhika TS: A spectrum of coexistent tuberculosis and carcinoma in the breast and axillary lymph nodes: report of five cases. Breast 2006;15 (3):437-439.

23 Ying-Hua Y, Wei W, Jian-Lun L: Diagnostic value of fine-needle aspiration biopsy for breast mass: a systematic review and meta-analysis. BMC Cancer 2012;12:41.

24 Uematsu T, Yuen S, Kasami M, Uchida Y: Comparison of magnetic resonance imaging, multidetector row computed tomography, ultrasonography, and mammography for tumor extension of breast cancer. Breast Cancer Res Treat 2008;112 (3):461-474.
5 Hamit HF, Ragsdale TH: Mammary tuberculosis. J R Soc Med 1982;75:764-765.

26 Banarjee SN, Ananthakrishnan N, Mehta RB, Prakash S: Tuberculous mastitis: a continuing problem. World J Surg 1987;11:105-109.

27 Gupta S, Singh VJ, Bhatia G, Dhuria K: Primary tuberculosis of the breast manifested as abscess: a rare case report. Acta Med Indones 2014;46 (1):51-53. 